\title{
Ruthenium, osmium and rhodium complexes of polypyridyl ligands: Metal-promoted activities, stereochemical aspects and electrochemical properties
}

\author{
PARIMAL PAUL \\ Discipline of Silicates and Catalysis, Central Salt and Marine Chemicals \\ Research Institute, G B Marg, Bhavnagar 364 002, India \\ e-mail: salt@csir.res.in
}

\begin{abstract}
This article presents a brief overview of the reactions of 2,4,6-tris(2pyridyl)-1,3,5-triazine (tptz) in presence of rhodium(III), ruthenium(II) and osmium(II) under various experimental conditions. Under certain experimental conditions tptz exhibits metal-assisted hydrolysis/hydroxylation at the triazine ring. However, synthetic methods have also been developed to prepare complexes with intact tptz. Molecular structures of some of the complexes, especially stereoisomers of the hydroxylated products, are established by single crystal X-ray studies. A critical analysis of all data suggests that the electron-withdrawing effect of the metal ion $(\mathrm{L} \rightarrow \mathrm{M} \sigma$ donation) is the predominant factor, rather than angular strain, that is responsible for metal-promoted reactivities. Electrochemical properties of all of these complexes have been investigated, $\mathrm{Rh}$ (III) complexes are excellent catalysts for electrocatalytic reduction of $\mathrm{CO}_{2}$, and dinuclear $\mathrm{Ru}$ (II) and $\mathrm{Os}$ (II) complexes exhibit strong electronic communication between the metal centres.
\end{abstract}

Keywords. 2,4,6-Tris(2-pyridyl)-1,3,5-triazine; metal-assisted reactions; ruthenium(II), osmium(II) and rhodium(III)/(II) complexes; crystal structure; electrochemistry.

\section{Introduction}

In recent years, ruthenium(II), osmium(II) and Rh(III) complexes of polypyridyl ligands have received much attention because of their rich electrochemical and photophysical properties, and their potential applications in various supramolecular structures as electronic and photomolecular devices ${ }^{1-7}$. Multinuclear systems of this kind can be developed by covalent linking of building blocks with spacers which, therefore, is the key component because the size, shape and electronic nature of the bridge controls the electronic communication between the chromophores and thereby the molecule as a whole. The ligand 2,4,6-tris(2-pyridyl)-1,3,5-triazine (tptz) is a potential spacer, which functions as a bis-bidentate or simultaneously as a tridentate and a bidentate bridging unit. The ligand tptz is believed to be stable towards nucleophilic attack and has been used as an analytical reagent for various metal ions ${ }^{8-11}$. A few mono and dinuclear complexes of ruthenium(II) of tptz has also been reported ${ }^{12-14}$. However, our studies reveal that under certain experimental conditions tptz undergoes various metal-assisted reactions ${ }^{15-19}$. Here, we briefly account the reactivities of tptz in presence of rhodium(III), ruthenium(II) and osmium(II), stereochemistry of the products, mechanistic aspects of hydrolysis/hydroxylation and electrochemical properties. 


\section{Experimental}

Materials, physical measurements and methods of preparation of all complexes (1-18) are described elsewhere ${ }^{15-18}$.

\section{Results and discussion}

\subsection{Synthesis and characterisation of rhodium(III) complexes ${ }^{15,16}$}

The mononuclear complexes of compositions $\left[\mathrm{Rh}(\mathrm{tptz}) \mathrm{Cl}_{3}\right](\mathbf{1})$ and $\left[\mathrm{Rh}(\mathrm{tptz})_{2}\right]\left(\mathrm{ClO}_{4}\right)_{3}(\mathbf{2})$ were synthesised by the reaction of tptz (figure 1a) and $\mathrm{RhCl}_{3}$ in ethanol and acetone respectively. During the synthesis of these complexes no nucleophilic attack at the triazine ring of tptz was observed. However, the reaction of the tptz and $\mathrm{RhCl}_{3}$ in refluxing ethanol-water resulted in the hydrolysis of tptz to [bis(2-pyridylcarbonyl)amide] anion (bpca) yielding $\mathrm{Rh}$ (III) as well as $\mathrm{Rh}$ (II) complexes, $\left[\mathrm{Rh}(\mathrm{bpca})_{2}\right]\left[\mathrm{PF}_{6}\right](3)$ and $\mathrm{Rh}(\mathrm{bpca})_{2}$ (4) respectively. The tptz of complex 1 was also hydrolysed when it was treated with $\left[\mathrm{Rh}(\right.$ tpy $\left.) \mathrm{Cl}_{3}\right]$ in ethanol-water and resulted in the formation of $\mathrm{Rh}(\mathrm{III})$ and $\mathrm{Rh}(\mathrm{II})$ complexes, $[\mathrm{Rh}(\mathrm{bpca})(\mathrm{tpy})]\left[\mathrm{PF}_{6}\right]_{2}$ (5) and $[\mathrm{Rh}(\mathrm{bpca})$ (tpy) $]\left[\mathrm{PF}_{6}\right](\mathbf{6})$, respectively. Hydrolysis of the tptz of complex 2 also occurred under similar experimental conditions yielding $\left[\mathrm{Rh}(\mathrm{bpca})_{2}\right]\left(\mathrm{ClO}_{4}\right)$. Molecular structures of complexes 1 (figure 1b), 3 (figure 1c), 4, 5, and $\mathbf{6}$ (figure 1d) were established by single crystal X-ray studies. Metal ions in these complexes show octahedral geometry in which tptz/bpca function as a tridentate ligand. Rhodium(II) complexes are interesting, the bpca moiety provides the necessary structural and electronic requirement to stabilise mononuclear paramagnetic $\mathrm{Rh}(\mathrm{II})$ complexes, otherwise it is extremely difficult to prepare using polypyridyl ligands. Complexes $\mathbf{4}$ and $\mathbf{6}$ are the first examples of structurally characterised mononuclear Rh(II) complexes with polypyridyl ligands.

\subsection{Synthesis and characterisation of ruthenium(II) and osmium(II) complexes ${ }^{18,19}$}

The reaction of $\mathrm{Ru}(\mathrm{bpy})_{2} \mathrm{Cl}_{2}$ and $\mathrm{Os}(\mathrm{bpy})_{2} \mathrm{Cl}_{2}$ with tptz (1:1 molar ratio) resulted in the formation of $\left[(\mathrm{bpy})_{2} \mathrm{Ru}(\mathrm{tptz})\right]\left(\mathrm{PF}_{6}\right)_{2} \quad(7)$ and $\left[(\mathrm{bpy})_{2} \mathrm{Os}(\mathrm{tptz})\right]\left(\mathrm{PF}_{6}\right)_{2} \quad(\mathbf{8})$, respectively. Interestingly, when similar experimental conditions were used to prepare binuclear complexes then an unexpected hydroxylation occurred at the carbon atom of the triazine ring, which resulted in the formation of $\left[\left\{\mathrm{Ru}(\mathrm{bpy})_{2}\right\}_{2}(\mathrm{tptz}-\mathrm{OH})\right]\left(\mathrm{PF}_{6}\right)_{3} \quad$ (9), $\left[\left\{\mathrm{Os}(\mathrm{bpy})_{2}\right\}_{2}(\mathrm{tptz}-\mathrm{OH})\right]\left(\mathrm{PF}_{6}\right)_{3} \quad(\mathbf{1 0})$ and the heterodinuclear complex [(bpy $)_{2} \mathrm{Ru}(\mathrm{tptz}-$ $\left.\mathrm{OH}) \mathrm{Os}(\mathrm{bpy})_{2}\right]\left(\mathrm{PF}_{6}\right)_{3}$ (11). Again, hydroxylation of tptz did not occur in the dinuclear complexes $\left[(\text { bpy })_{2} \mathrm{Ru}(\mathrm{tptz}) \mathrm{Ru}(\mathrm{tpy})\right]\left(\mathrm{PF}_{6}\right)_{4} \quad(\mathbf{1 2})$ and $\left[(\mathrm{bpy})_{2} \mathrm{Os}(\mathrm{tptz}) \mathrm{Ru}(\mathrm{bpy})_{2}\right]\left(\mathrm{PF}_{6}\right)_{4} \quad$ (13) when they were synthesised by the reaction of $[(\text { tpy }) \mathrm{Ru}(\mathrm{tptz})]^{2+}$ and $\mathrm{Ru}(\mathrm{bpy})_{2} \mathrm{Cl}_{2} /$ $\mathrm{Os}(\mathrm{bpy})_{2} \mathrm{Cl}_{2}$ under the above reaction conditions. However, hydroxylation of tptz occurred when an attempt was made to prepare the same compound following a different route, as the reaction of $\left[(\mathrm{tpy}) \mathrm{RuCl}_{3}\right]$ and $\left[(\mathrm{bpy})_{2} \mathrm{Ru}(\mathrm{tptz})\right]^{2+}$ under similar experimental conditions yielded $\left[(\text { bpy })_{2} \mathrm{Ru}(\right.$ tptz-OH $\left.) \mathrm{Ru}(\mathrm{tpy}) \mathrm{Cl}\right]\left(\mathrm{PF}_{6}\right)_{2}$ (14). The trinuclear complexes without hydroxylation of tptz, $\left.\left[(\mathrm{bpy})_{2} \mathrm{M}(\mathrm{tptz})\right\}_{2} \mathrm{Ru}\right]\left(\mathrm{PF}_{6}\right)_{6}(\mathrm{M}=\mathrm{Ru}(\mathbf{1 5})$, Os (16)), were obtained by the reaction of $\left[(\text { bpy })_{2} \mathrm{M}(\mathrm{tptz})\right]^{2+}$ with $\left.\left[\mathrm{RuCl}_{2} \text { (DMSO }\right)_{4}\right](2: 1$ ratio) in 2methoxyethanol. However, attempt to obtain the same compound using $\mathrm{RuCl}_{3}$ instead of $\left[\mathrm{RuCl}_{2}(\mathrm{DMSO})_{4}\right]$ in ethanol-water resulted in hydroxylation of tptz. All of these complexes were characterized by analytical and spectroscopic methods ${ }^{18,19}$. Molecular 

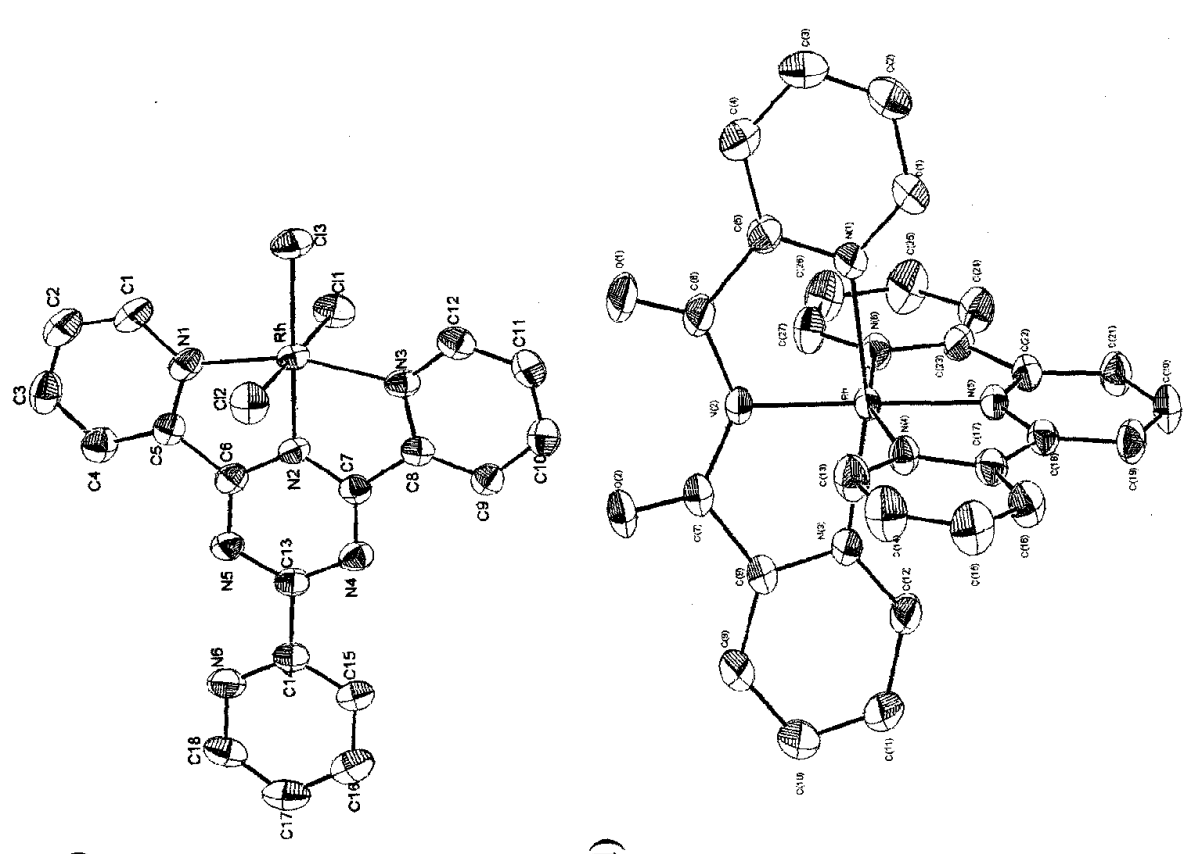

e

อ

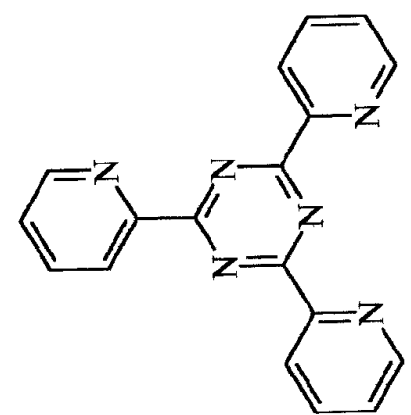

త

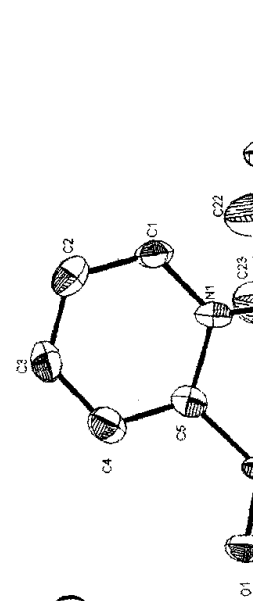

(2)

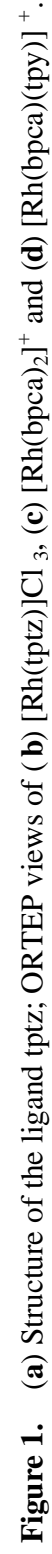


structures of many of these complexes were determined crystallographically and some of the structures are shown in the following section.

\section{Stereochemistry of the dinuclear complexes ${ }^{18}$}

Octahedral metal centres with bidentate ligands generally show stereoisomerism ${ }^{20}$. The homodinuclear complexes $\mathbf{9}$ and 10, where the coordination environments of the metal centres is equivalent, exist in two diastereoisomeric forms $\Delta \Lambda$ (meso) and $\Delta \Delta / \Lambda \Lambda$ (rac), which arise due to the different orientation of the pyridyl rings with respect to the plane of the bridging ligand. Both the meso and rac isomers were isolated in pure form by repeated partial crystallisation and were characterised by ${ }^{1} \mathrm{H}$ NMR and crystallographic studies. The PLUTO views of the meso and rac isomers of $\mathbf{1 0}$ are shown in figures $2 \mathrm{a}$ and $2 \mathrm{~b}$. The optical isomers ( $d$ and $l$ ) of complex 9 are shown in figures $2 \mathrm{c}$ and $2 \mathrm{~d}$.

The NMR spectroscopy was found to be a useful technique to differentiate stereoisomers. The ${ }^{1} \mathrm{H}$ NMR spectra of meso and rac forms show significant difference, specially $\mathrm{OH}$ and some $\mathrm{H}_{3}$ and $\mathrm{H}_{6}$ protons (usual numbering of bipyridyl is used), due to different orientation of the pyridyl rings. The electronic spectra of meso and rac forms are similar but not the same. A slight difference in $\lambda_{\max }$ and molar absorption $(\varepsilon)$ is observed, similar observation was also noted by Keene et $a l^{21}$. However, no observable difference in the electrochemistry of meso and rac isomers is noted.

\section{Mechanistic aspects of the hydrolysis/hydroxylation}

Triaryltriazenes are usually stable towards hydrolysis ${ }^{22}$, however, it does occur under certain experimental conditions in the presence of some metal ions. It was first observed by Lerner and Lippard in aqueous media in the presence of $\mathrm{Cu}(\mathrm{II})^{23}$ and the structure of this complex with one hydrolysed tptz (bpca) was established crystallographically ${ }^{24}$. On the basis of $\mathrm{Cu}-\mathrm{N}$ bond distances and angles at the carbonyl carbon atoms within the chelate ring (A $\alpha$, figure 3a) of this compound it was suggested that co-ordination of tptz induces an angular strain allowing nucleophilic attack at the carbon atoms of the triazine ring by the solvent resulting in the hydrolysis of tptz. Crystallographic data of our $\mathrm{Ru}(\mathrm{II})$ (figure 3b) and $\mathrm{Rh}(\mathrm{III})$ (figure 3c) complexes with intact tptz and also $\mathrm{Rh}(\mathrm{III})$ complexes (figure 3d) with hydrolysed tptz suggest that the angular strain experienced by $\mathrm{Ru}(\mathrm{II})$ and $\mathrm{Rh}$ (III) complexes are comparable and are similar to that of $\mathrm{Cu}(\mathrm{II})$ complex. Therefore, on the basis of strain factor alone one cannot explain the hydrolysis of tptz only in the $\mathrm{Rh}$ (III) complexes and not in the $\mathrm{Ru}(\mathrm{II})$ complex under similar experimental conditions. This suggests that the metal ion plays a major role in the hydrolysis of tptz. In the Rh(III) complexes the electron-withdrawing effect of the metal ion results in an enhanced electrophilicity on the carbon atoms $\left(\mathrm{C}^{\delta+}\right)$ adjacent to the metal-bound nitrogen atom of the triazine ring, thus making it susceptible to nucleophilic attack. In the $\mathrm{Ru}(\mathrm{II})$ complex, the metal ion has the ability to form $\pi$-back-bonding with unsaturated ligands compensating partially for the $\sigma$-electron-withdrawing effect. As a result, the electrophilicity on the carbon atom in question is not sufficient to make it susceptible to nucleophilic attack. The $\pi$ back-bonding in the $\mathrm{Rh}(\mathrm{III})$ is apparently not effective. The crystal structures of $\mathrm{Ru}(\mathrm{II})$ and $\mathrm{Rh}(\mathrm{III})$ with intact tptz show the presence of two water molecules in the lattice at similar sites. In the $\mathrm{Rh}(\mathrm{III})$ complex, both the water molecules

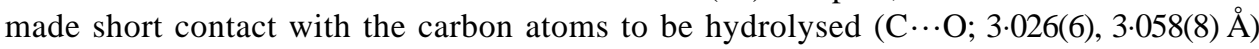
thus making it a model close to the 'intermediate' of hydrolysis by nucleophilic attack. 

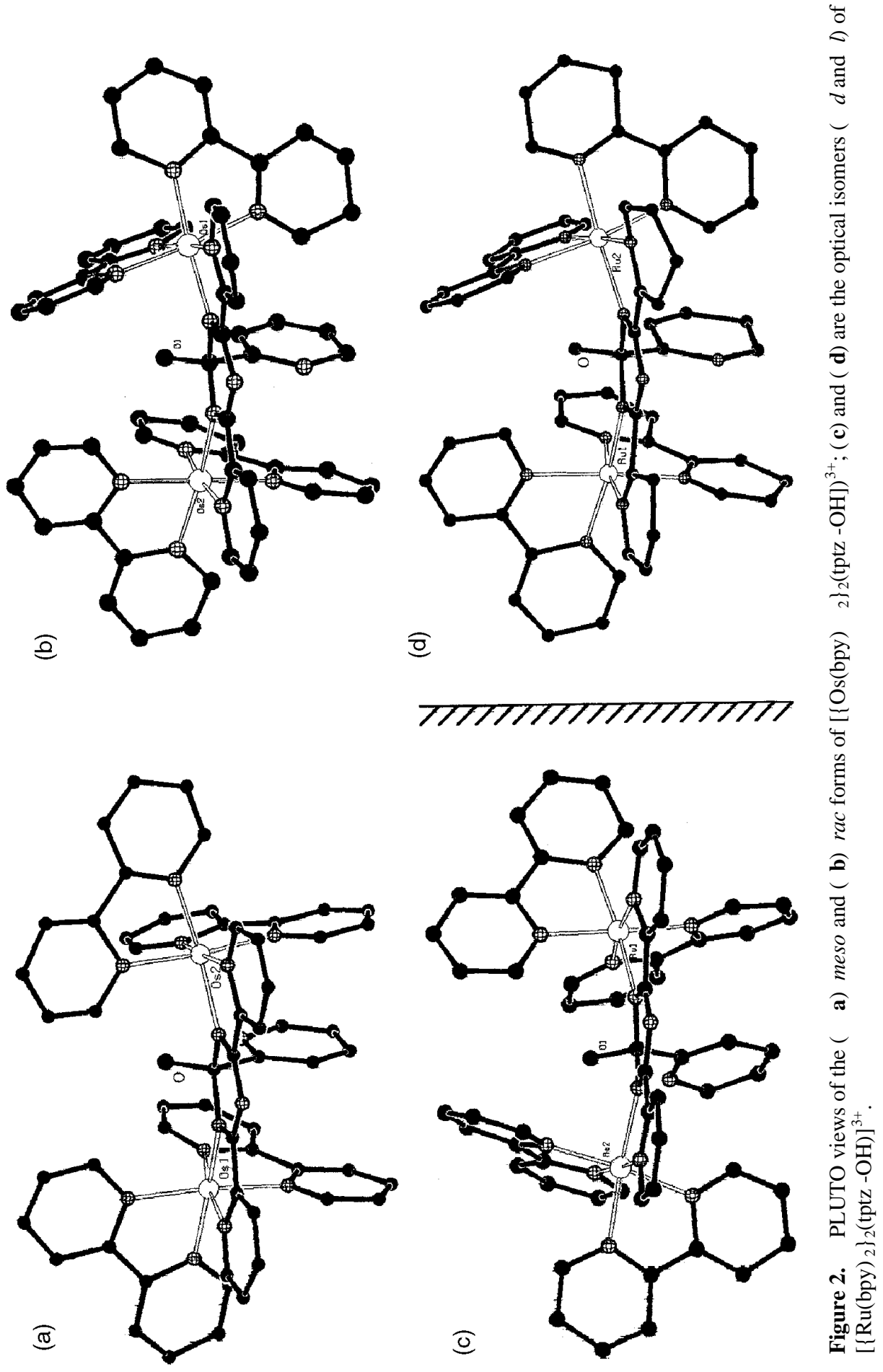
(a)

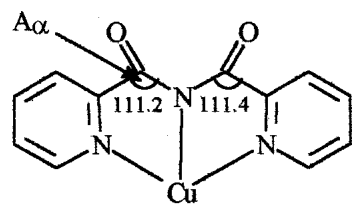

(c)<smiles></smiles>

(b)<smiles>CC1=Nc2nc(C)nnc2N2C=CC=CC2=N1</smiles>

(d)

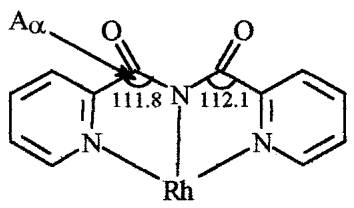

Figure 3. Drawings showing the relevant structural portions of complexes (a) $[\mathrm{Cu} \text { (bpca)(2-picolinamide) }]^{+}$(from ref. 24), (b) $\left[\mathrm{Ru}(\mathrm{tptz})_{2}\right]^{2+}$ (from ref. 15), (c) $\left[\mathrm{Rh}(\mathrm{tptz}) \mathrm{Cl}_{3}\right.$ and $(\mathbf{d})\left[\mathrm{Rh}(\mathrm{bpca})_{2}\right]^{+}$.

However, in the $\mathrm{Ru}(\mathrm{II})$ complex, the water molecules do not show any significant interaction with the carbon atoms $(\mathrm{C} \cdots \mathrm{O} ; 3.908 \AA)$, indicating that the carbon atoms are not sufficiently electropositive to interact with the water molecule effectively.

Hydroxylation at the carbon atom of the triazine ring of tptz occurred in the binuclear complexes of $\mathrm{Ru}(\mathrm{II})$ and $\mathrm{Os}(\mathrm{II})$, where tptz is used as a spacer between the two building blocks (figure 2). Interestingly, hydroxylation at the triazine ring did not occur in the mononuclear complexes under similar experimental conditions. This difference could be due to $\pi$ back-bonding effect of metal ion. As mentioned above, this effect reduces electrophilicity on the carbon atoms, however, at least some resultant electron deficiency makes these carbon atoms electropositive $\left(\mathrm{C}^{\delta+}\right)$ to some degree. Such an effect from one metal centre may not be sufficient to make the carbon atom susceptible to nucleophilic attack but the combined effect from both sides in the dinuclear complexes possibly makes the carbon atom an electrophilic centre. As a result, hydroxylation occurs in the dinuclear complexes but not in the corresponding mononuclear ones. The other factor is the steric hindrance due to overcrowding of a number of pyridyl rings, hydroxylation creates tetrahedral geometry around the carbon atom and provides significant relief to the overcrowding.

\section{Electrochemistry}

Cyclic voltammograms of all of the Rh(III) complexes were recorded in argon and carbon dioxide saturated solutions. In an argon atmosphere they show a metal-based composite wave in the range -0.42 to $-0.98 \mathrm{~V}$ (vs SCE) corresponding to $2 e$ reduction $(\mathrm{Rh}(\mathrm{III}) \rightarrow \mathrm{Rh}(\mathrm{I}))$ and a ligand-based one electron redox couple. In the $\mathrm{CO}_{2}$ saturated solution they exhibit a new cathodic peak in the potential range -1.26 to $-1.44 \mathrm{~V}$ with a large enhancement of current, indicating electrocatalytic reduction of $\mathrm{CO}_{2}$. The reduction of $\mathrm{CO}_{2}$ in $\mathrm{DMF}$ in the absence of catalyst occurs at a potential more negative than $-2 \cdot 0 \mathrm{~V}^{25}$. A significant anodic shift of the reduction potential of $\mathrm{CO}_{2}$ in presence of metal ion indicates strong electrocatalytic effect. Controlled potential $\mathrm{CO}_{2}$ reduction catalysis 
experiments were performed, the product was identified as formate and the turnover frequencies were 6.8 to 10.8 (moles of formate produced per mole of catalyst per hour).

Mononuclear $\mathrm{Ru}(\mathrm{II})$ and $\mathrm{Os}(\mathrm{II})$ complexes exhibit a metal-based oxidation $(\mathrm{M}(\mathrm{II}) \rightarrow \mathrm{M}(\mathrm{III}))$ at +1.42 and $+0.97 \mathrm{~V}$ for $\mathrm{Ru}(\mathrm{II})$ and $\mathrm{Os}(\mathrm{II})$ respectively, and three ligand-based redox couples in the potential range -0.73 to $-1.64 \mathrm{~V}$. In the dinuclear complexes two metal-based one-electron oxidations and five ligand-based reductions were observed. In symmetric homodinuclear complexes, like $\mathbf{9}$ and 10, the splitting of the metal-based oxidation wave indicates electronic communication between the metal centres and the extent of splitting reflects the degree of metal-metal interaction. The comproportionation constant $\left(K_{\text {com }}\right)$ of $6.03 \times 10^{4}-4.70 \times 10^{6}$ of the mixed valence species suggest strong electronic coupling between the metal centres. The ligand tptz has a low-lying $\pi^{*}$ orbital; therefore, metal-metal communication through the bridge by an electron transfer mode across the low-lying $\pi^{*}$ orbital of the bridging ligand probably occurs.

\section{Conclusions}

The reactions of 2,4,6-tris(2-pyridyl)-1,3,5-triazine with $\mathrm{Rh}(\mathrm{III}), \mathrm{Ru}(\mathrm{II})$ and $\mathrm{Os}(\mathrm{II})$ under various experimental conditions revealed metal-assisted unusual reactivities of the ligand. However, methods have also been developed to prepare metal complexes with intact tptz. Formation of stable mononuclear paramagnetic Rh(II) complexes is quite interesting, otherwise it is very difficult to prepare, specially with polypyridyl ligands. Isolation of the stereoisomeric forms of the dinuclear $\mathrm{Ru}(\mathrm{II})$ and $\mathrm{Os}(\mathrm{II})$ complexes and their spectroscopic and crystallographic characterization is noteworthy. For metal-promoted activities, the electron-withdrawing effect of the metal ion seems to be the predominant factor rather than angular strain. One of the important findings is that the $\mathrm{Rh}(\mathrm{III})$ complexes exhibit effective catalytic property in the electrocatalytic reduction of carbon dioxide. The electrochemical studies of the dinuclear $\mathrm{Ru}(\mathrm{II})$ and $\mathrm{Os}(\mathrm{II})$ complexes suggest strong metal-metal electronic interaction mediated by the bridging ligand. Since this ligand (tptz) shows various metal-promoted activities, therefore, in future one should be careful in using this ligand as an analytical reagent for estimation of metal ion.

\section{Acknowledgements}

Financial assistance received from the Department of Science and Technology, New Delhi, is gratefully acknowledged. The author thanks Drs B Tyagi, A K Bilakhiya, E Suresh, M M Bhadbhade and P Dastidar for their contributions to this project, and Drs P K Ghosh and R V Jasra for their interest and encouragment.

\section{References}

1. Balzani V, Juris A, Venturi M, Campagna S and Serroni S 1996 Chem. Rev. 96759

2. Venturi M, Serroni S, Juris A, Campagna S and Balzani V 1998 Top. Curr. Chem. 197193

3. DeCola L and Belser P 1998 Coord. Chem. Rev. 177301

4. Balzani V, Campagna S, Denti G, Juris A, Serroni S and Venturi M 1998 Acc. Chem. Res. 31 26

5. Belser P, Bernhard S, Blum C, Beyeler A, DeCola L and Balzani V 1999 Coord. Chem. Rev. 190-192 155

6. Barigelletti F and Flamigni L 2000 Chem. Soc. Rev. 291 
7. El-Ghayoury A, Harriman A, Khatyr A and Ziessel R 2000 Angew. Chem., Int. Ed. Engl. 39 185

8. Collins P and Diehl H 1960 Anal. Chem. Acta 2125

9. Diehl H, Buchanan E B Jr. and Smith G F 1960 Anal. Chem. 321117

10. Embry W A and Ayres G H 1968 Anal. Chem. 401499

11. Janmohamed M J and Ayres G H 1972 Anal. Chem. 442263

12. Thomas N C, Foley B L and Rheingold A L 1988 Inorg. Chem. 273426

13. Chirayil S, Hegde V, Jahng Y and Thummel R P 1991 Inorg. Chem. 302821

14. Berger R M, Ellis II D D 1996 Inorg. Chim. Acta 2411

15. Paul P, Tyagi B, Bhadbhade M M and Suresh E 1997 J. Chem. Soc., Dalton Trans. 2273

16. Paul P, Tyagi B, Bilakhiya A K, Bhadbhade M M, Suresh E and Ramachandraiah G 1998 Inorg. Chem. 375733

17. Paul P, Tyagi B, Bilakhiya A K, Bhadbhade M M and Suresh E 1999 J. Chem. Soc., Dalton Trans. 2009

18. Paul P, Tyagi B, Bilakhiya A K, Dastidar P and Suresh E 2000 Inorg. Chem. 3914

19. Bilakhiya A K, Tyagi B, Agnihotri P, Suresh E, Dastidar P and Paul P (in press)

20. Keene F R 1997 Coord. Chem. Rev. 166121

21. Kelso L S, Reitsma D A, Keene F R 1996 Inorg. Chem. 355144

22. Smolin E M, Rapoport L S 1959 Triazines and derivatives (New York: Interscience) p. 163

23. Lerner E I and Lippard S J 1976 J. Am. Chem. Soc. 985397

24. Faus J, Julve M, Amigo J M and Debaerdemaeker T 1989 J. Chem. Soc., Dalton Trans. 1681

25. Arana C, Yan S, Keshavart K M, Potts K T and Abruna H D 1992 Inorg. Chem. 313680 